\title{
Efficacy of a medical genetics rotation during pediatric training
}

\author{
Joanne Nguyen, MD1' Jennifer Lemons, MS1, Sharon Crandell, MD², and Hope Northrup, MD'
}

Purpose: With the greater understanding that genetics underlies the basis of health and disease, the practice of medicine is changing such that we are now in an era of genomic medicine. However, there has been a deficiency of training in genetics and genomics among primary care residents.

Methods: We describe the experience of our institution, which requires pediatric, child neurology, and medicine-pediatric residents to complete a subspecialty rotation in medical genetics. Standardized end-of-rotation evaluation results were analyzed and thematic analysis was performed.

Results: The mean overall educational quality of the rotation rated on a 5-point scale ranging from 1 (poor) to 5 (excellent) was 4.49 . The participation in medical genetics had three main outcomes: (i) a variety of learning opportunities were presented such that it was one of the most educational rotations that trainees experienced; (ii) both trainee competence and confidence in clinical practice improved through knowledge gained; and (iii) an increased awareness and appreciation for interprofessional relationships, especially for the genetic counseling profession, was highly valued. In addition, some residents have gone on to choose medical genetics as a profession.

Conclusion: A rotation in medical genetics increases knowledge and awareness of the importance that medical genetics has in clinical practice.

Genet Med advance online publication 14 May 2015

Key Words: genetics rotation; genetics training; interprofessional; pediatric residents; teaching
Genomics contributes to health and disease and offers the opportunity for truly personalized medicine. However, the rapidly advancing field of medical genetics is outpacing the knowledge acquisition of practitioners. ${ }^{1}$ Given its impact, it is essential for practitioners to be knowledgeable regarding genetics and to be capable of applying the information to clinical practice. Unfortunately, there are fewer than 3,000 certified specialists in medical genetics in the United States. ${ }^{2}$ Thus, there have been movements for primary care physicians to become competent in genetics and genomics. ${ }^{3-7}$ Medical genetics can no longer be considered a field of rare disorders given that genetics underlies all of medicine. Thus, practitioners should consider genetics during every patient encounter. ${ }^{8,9}$

Some effort has been made to improve awareness among practitioners..$^{10}$ Historically, however, there has been a deficiency of training in medical genetics among primary care residents. We describe the experience of our institution, which requires all categorical pediatric, child neurology, and combined medicine-pediatric residents to complete a subspecialty rotation in medical genetics. The exposure to our field not only increases knowledge and awareness of the importance of genetics but also provides the opportunity to assess how genetics impacts trainees within their chosen discipline.

\section{MATERIALS AND METHODS}

Like all clinical rotations at the University of Texas Medical School at Houston, the pediatric residency program's subspecialty rotation in medical genetics has an online evaluation form for rating the quality and effectiveness of the rotation. Standardized end-of-rotation evaluations have been available for more than 9 years. Results are based on a numbered scale as well as free-text comments. These reports were analyzed from July 2005 to March 2015. Thematic analysis of the comments during this time period was also performed. This study was approved by the UT Health Committee for the Protection of Human Subjects.

\section{RESULTS}

\section{Training program}

Our Graduate Medical Education (GME) program requires first-year categorical pediatric, first-year child neurology, and fourth-year combined medicine-pediatric trainees to complete a medical genetics rotation. The rotation was 1 month in length until July 2013, when this changed to a 2-week rotation owing to factors unrelated to the rotation. The categorical pediatric residency program has 22 residents per year, the combined medicine-pediatric residency program has 6 residents per year, and the child neurology residency program has 3 residents per year. The service comprises both outpatient and inpatient encounters for a wide scope of general and subspecialty genetics indications. The team has a variety of learners, including medical students, genetic counseling students, medical genetics and combined pediatrics-medical genetics residents, as well as maternal-fetal medicine, molecular genetic pathology, and

${ }^{1}$ Division of Medical Genetics, Department of Pediatrics, University of Texas Medical School at Houston, Houston, Texas, USA; ${ }^{2}$ Division of Neonatal-Perinatal Medicine,

Department of Pediatrics, University of Texas Medical School at Houston, Houston, Texas, USA. Correspondence: Joanne Nguyen (Joanne.V.Nguyen@uth.tmc.edu)

Submitted 25 February 2015; accepted 8 April 2015; advance online publication 14 May 2015. doi:10.1038/gim.2015.65 
pediatric endocrinology fellows. These trainees are supervised by and interact with two or three MD geneticists, five certified genetic counselors, one genetics nurse, and one dietitian. We provide physical space for the trainees to work in, which has a library, computers, printer, and telephone.

At the start of their rotation, trainees are given an orientation by a genetic counselor or genetics nurse, and they receive a rotation manual. The manual includes a directory of contact information for the members of the Division of Medical Genetics; schedules of outpatient clinics, inpatient consultation rounds, and teaching conferences; a list adapted from the Texas Department of State Health Services titled "When Does a Child Need Genetic Services?" (Supplementary Table S1 online); and an article explaining how to take pedigrees. ${ }^{11}$ Additional references and materials are available to them online, including the goals and objectives of the rotation (Supplementary Table S2 online), articles from the series "Elements of Morphology: Human Malformation Terminology," ${ }^{2-17}$ as well as a list of resources that they have access to in our library, such as textbooks, computer databases, and helpful websites (Table 1).

The philosophy of the medical genetics rotation is twofold: teach the resident to recognize when a patient may have a disorder with an underlying genetic etiology and provide the resident with the tools to initiate the evaluation for a patient who may have a genetic condition. There are thousands of conditions with a genetic component, ranging from chromosomal to single-gene to multifactorial conditions. The medical genetics rotation will not teach the resident about every one of those conditions. We seek to teach the approach to a genetic problem and familiarity with some of the more common conditions.

Each trainee is assigned 5-10 outpatients and up to 5 inpatients per week; these numbers can vary from week to week. Although trainees are assigned to different patients, learners are present to hear one another's cases in order to benefit from their

\section{Table 1 Suggested resources}

\begin{tabular}{ll}
\hline Textbooks & Smith's Recognizable Patterns of Human \\
& Malformation \\
& Greenwood Genetic Center Growth \\
& References \\
& Management of Genetic Syndromes \\
& Emery and Rimoin's Principles and Practice of \\
& Medical Genetics \\
& Atlas of Inherited Metabolic Diseases \\
& Genetics in Primary Care and Clinical Medicine \\
& Catalogue of Unbalanced Chromosome \\
& Aberrations in Man \\
& Gorlin's Syndromes of the Head and Neck \\
& Radiology of Syndromes, Metabolic Disorders, \\
& and Skeletal Dysplasias \\
& Bone Dysplasias: An Atlas of Genetic Disorders \\
of Skeletal Development & \\
Gene Reviews; Genetics Home Reference; & OMIM \\
Online & POssuM; London Dysmorphology \\
\hline Databases &
\end{tabular}

team members' teaching points. Because a trainee is involved in every patient encounter, the approach to a patient is practiced, providing real examples applied to patient care. Each week, trainees give case presentations during two teaching conferences. At the end of their rotation, they prepare and deliver a formal genetics grand rounds presentation. Upon completion, trainees submit an online evaluation of the rotation and the supervisors. In turn, the faculty provides individual feedback and evaluations for each trainee.

\section{Evaluations}

Aggregate results of rotation evaluations by trainees for 9 consecutive years are listed in Table 2. The mean overall educational quality of the rotation rated on a 5-point scale ranging from 1 (poor) to 5 (excellent) was 4.49 ( $n=193$ responses). This positive learning experience was supported by the trainees' comments during the same period (Supplementary Table S3 online). Analysis of the comments showed three main themes: (i) a variety of learning opportunities were presented such that it was one of the most educational rotations that trainees experienced; (ii) both trainee competence and confidence in clinical practice improved through knowledge gained; and (iii) trainees gained an increased awareness of and appreciation for interprofessional relationships, especially in the genetic counseling profession.

\section{DISCUSSION}

There is a need for practitioners who are competent in genetics, but there is a severe lack of exposure to medical genetics. Our program trains and mentors practitioners with respect to genetics as a salient component of pediatric primary and subspecialty care. Rotation-specific feedback has provided an eye-opening glimpse into how formative this rotation can be, mainly pertaining to competency gained in knowledge of clinical genetics, laboratory testing, obtaining a family history, attention to detail during a physical examination, recognizing dysmorphic features, identifying genetics resources, ordering basic genetic testing, and determining appropriate referrals. For example, one rotator said that after the rotation, "I feel more comfortable with working up a child that may have a genetic disorder and looking for signs on a physical exam." Another noted that the rotation "gave us a good insight on different resources that are available for genetic disorders and what tests to order." Another rotator provided this rewarding comment: "This rotation really is 'medicine.' You have to have a firm grip on genetics, physiology, pathophysiology, and medical management." Given that the rotation occurs during the first year for the pediatric residents, it equips them to apply this knowledge during the remainder of their training. Trainees also described positive interactions with our genetic counselors, genetics nurse, and metabolic dietitians, making their overall experiences more enjoyable. Building interprofessional relationships is an important component of professional development.

However, several limitations were noted in the evaluations. For example, a frequent comment was that the 2-week 
Table 2 Rotation evaluation results

\begin{tabular}{|c|c|c|}
\hline Question & $\begin{array}{l}\text { Mean } \\
\text { score }\end{array}$ & Rating scale \\
\hline Were the number and diversity of patients adequate to provide a well-rounded educational experience? & 1.98 & 1: no-2: yes \\
\hline The workload on this rotation was appropriate for my level of training. & 1.99 & 1: no-2: yes \\
\hline I was appropriately supervised in my patient care activities by the attending physician and/or senior level residents. & 1.99 & 1: no-2: yes \\
\hline X-rays were readily available. & 1.98 & 1: no-2: yes \\
\hline $\begin{array}{l}\text { Did you feel that the number and diversity of patients were adequate to provide a well-rounded educational } \\
\text { experience? }\end{array}$ & 1.98 & 1: no-2: yes \\
\hline Was the clinic organized? & 1.98 & 1: no-2: yes \\
\hline Were there any difficulties in scheduling patients for you? & 1.29 & 1: no-2: yes \\
\hline Educational goals for this rotation were clearly stated. & 1.98 & 1: no-2: yes \\
\hline \multirow{2}{*}{ Teaching rounds were organized. } & & 2: some of the time \\
\hline & & 3: all of the time \\
\hline \multirow[t]{3}{*}{ Problem-based learning was encouraged on the rotation. } & 2.88 & 1: none of the time \\
\hline & & 2: some of the time \\
\hline & & 3: all of the time \\
\hline \multirow[t]{3}{*}{ The subspecialty conferences were educationally useful. } & 2.88 & 1: none of the time \\
\hline & & 2: some of the time \\
\hline & & 3: all of the time \\
\hline Overall educational quality of rotation & 4.49 & 1: poor-5: excellent \\
\hline
\end{tabular}

rotation was too short. Also, several trainees said they wanted more patients because the case load was variable, depending on factors such as the number of trainees on the service at a given time, whether their assigned clinic patients were present for appointments, and how many inpatient consultations were requested during their rotation.

Before starting the rotation, the genetic counseling students are required to take a quiz to assess their level of knowledge in medical genetics. However, this is not enforced for the residents, nor is there an assessment after completion of the rotation. A weakness of the study is a lack of pre- and post-rotation learner assessments or objective measures of the rotation.

Most studies have focused on the lack of knowledge in the subject of genetics and barriers to implementing genetics into practice. ${ }^{18-20}$ Unfortunately, the American Board of Pediatrics and the Pediatric Residency Review Committee of the Accreditation Counsel on Graduate Medical Education do not require medical genetics training. We are therefore one of the only pediatric programs in the United States to require medical genetics training. As such, we suggest a global appeal to the agencies involved in GME demonstrating the importance of this training. If medical genetics training is not required in an age of genomic medicine, a steadily increasing knowledge gap will exist among practitioners that will ultimately affect the quality of patient care. Given the impact that medical genetics can have on a patient's medical management, it would be in the patient's best interest to have practitioners who are competent in applying genetics and genomics to their practice as well as in recognizing when subspecialty referral is appropriate.

Medical genetics education should also be a foundation for all individuals assessing children. Among admissions to children's hospitals, $54-71 \%$ of patients have a genetic disorder. $^{21,22}$ However, we understand the limitations of programs, given that medical genetics is not available at every training institution. The US Secretary for Health and Human Services Advisory Committee on Heritable Disorders in Newborns and Children recognizes that geneticists who could provide training are not available in many residency programs. ${ }^{4}$ Alternative educational methods may be explored, including online training, partnership with other training programs via Web-based conferences, and incorporation of material into activities related to board certification or maintenance of certification. ${ }^{4,23}$ Several pediatric residents from other institutions have completed our rotation as a 1-month away elective, but we have not developed a program to offer this experience to residents remotely. Future directions may be to create such opportunities for external trainees. Having our medical genetics division within the Department of Pediatrics facilitated the incorporation of the pediatric residents into our specialty. A future aim would be to expand the rotation to include additional primary-care residents, such as those in family medicine, internal medicine, obstetrics/gynecology, and/or psychiatry.

Our rotation meets many of the competencies in genomics ${ }^{5}$ for practitioners of all disciplines. This will become increasingly 
applicable as genetics gains more awareness and recognition across specialties and subspecialties. We expect that this will result in more positive attitudes toward the discipline and attract potential medical geneticists. In fact, categorical pediatric residents have switched to the combined medical genetics-pediatric residency program after completing the rotation. Because this exposure increases knowledge and awareness of the importance that medical genetics has in clinical practice, a similar approach should be considered for other training programs. Further studies of additional models of medical genetics training for teaching institutions are needed.

\section{SUPPLEMENTARY MATERIAL}

Supplementary material is linked to the online version of the paper at http://www.nature.com/gim

\section{DISCLOSURE}

The authors declare no conflict of interest.

\section{REFERENCES}

1. Chesney RW, Friedman A, Kanto WP Jr, Stanton BF, Stull TL; Association of Medical School Pediatric Department Chairs, INC. Pediatric practice and education in the genomic/postgenomic era. J Pediatr 2002;141:453-458.

2. American Board of Medical Genetics and Genomics. Number of Certified Specialists in Genetics, 2013. http://www.abmgg.org/pages/resources_ certspecial.shtml. Accessed 1 March 2015.

3. Kaye C, Korf B. Genetic literacy and competency. Pediatrics 2013;132(suppl 3):S224-S230.

4. Kemper AR, Trotter TL, Lloyd-Puryear MA, Kyler P, Feero WG, Howell RR. A blueprint for maternal and child health primary care physician education in medical genetics and genomic medicine: recommendations of the United States secretary for health and human services advisory committee on heritable disorders in newborns and children. Genet Med 2010;12:77-80.

5. Korf BR, Berry AB, Limson M, et al. Framework for development of physician competencies in genomic medicine: report of the Competencies Working Group of the Inter-Society Coordinating Committee for Physician Education in Genomics. Genet Med 2014;16:804-809.

6. Riegert-Johnson DL, Korf BR, Alford RL, et al. Outline of a medical genetics curriculum for internal medicine residency training programs. Genet Med 2004;6:543-547
7. Saul RA. Genetic and genomic literacy in pediatric primary care. Pediatrics 2013;132(suppl 3):S198-S202.

8. Pletcher BA, Toriello HV, Noblin SJ, et al. Indications for genetic referral: a guide for healthcare providers. Genet Med 2007;9:385-389.

9. Scott J, Trotter T. Primary care and genetics and genomics. Pediatrics 2013;132(suppl 3):S231-S237.

10. Laberge AM, Fryer-Edwards K, Kyler P, Lloyd-Puryear MA, Burke W. Long-term outcomes of the "Genetics in Primary Care" faculty development initiative. Fam Med 2009;41:266-270.

11. Bennett RL, French KS, Resta RG, Doyle DL. Standardized human pedigree nomenclature: update and assessment of the recommendations of the National Society of Genetic Counselors. J Genet Couns 2008;17:424-433.

12. Allanson JE, Cunniff C, Hoyme HE, McGaughran J, Muenke M, Neri G. Elements of morphology: standard terminology for the head and face. Am J Med Genet A 2009;149A:6-28.

13. Hall BD, Graham JM Jr, Cassidy SB, Opitz JM. Elements of morphology: standard terminology for the periorbital region. Am J Med Genet A 2009;149A:29-39.

14. Hunter A, Frias JL, Gillessen-Kaesbach $G$, Hughes $H$, Jones KL, Wilson L. Elements of morphology: standard terminology for the ear. Am J Med Genet $A$ 2009;149A:40-60.

15. Hennekam RC, Cormier-Daire V, Hall JG, Méhes K, Patton M, Stevenson RE. Elements of morphology: standard terminology for the nose and philtrum. Am J Med Genet A 2009;149A:61-76.

16. Carey JC, Cohen MM Jr, Curry CJ, Devriendt K, Holmes LB, Verloes A. Elements of morphology: standard terminology for the lips, mouth, and oral region. Am J Med Genet A 2009:149A:77-92.

17. Biesecker LG, Aase JM, Clericuzio C, Gurrieri F, Temple IK, Toriello H. Elements of morphology: standard terminology for the hands and feet. Am J Med Genet $A$ 2009;149A:93-127.

18. Burke S, Stone A, Bedward J, Thomas H, Farndon P. A "neglected part of the curriculum" or "of limited use" ? Views on genetics training by nongenetics medical trainees and implications for delivery. Genet Med 2006; 8:109-115.

19. Hofman KJ, Tambor ES, Chase GA, Geller G, Faden RR, Holtzman NA. Physicians' knowledge of genetics and genetic tests. Acad Med 1993;68:625-632.

20. Metcalfe S, Hurworth R, Newstead J, Robins R. Needs assessment study of genetics education for general practitioners in Australia. Genet Med 2002;4:71-77.

21. McCandless SE, Brunger JW, Cassidy SB. The burden of genetic disease on inpatient care in a children's hospital. Am J Hum Genet 2004;74:121-127.

22. Soneda A, Teruya H, Furuya N, et al. Proportion of malformations and genetic disorders among cases encountered at a high-care unit in a children's hospital. Eur J Pediatr 2012;171:301-305.

23. Patay BA, Topol EJ. The unmet need of education in genomic medicine. Am J Med 2012;125:5-6. 